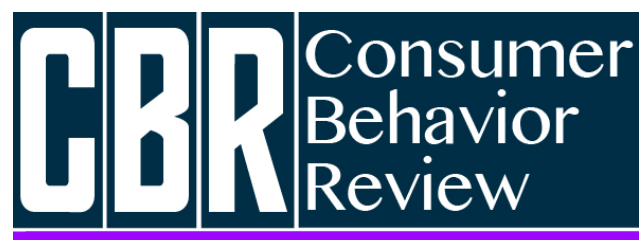

Revista Comportamento do Consumidor
Scussel, F. B. C. (2019). Is Consumer Experience the Next Best Thing? Reflections from a systematic review and research agenda proposition. Consumer Behavior Review, $3(2), 57-69$.
ISSN: 2526-7884

Editor: Prof. Dr. Marconi Freitas da Costa Journal's e-mail: cbr@ufpe.br
Evaluation: Double blind review

Received: 20 de maio de 2019

Accepted: 27 de agosto de 2019

\title{
IS CONSUMER EXPERIENCE THE NEXT BEST THING? REFLECTIONS FROM A SYSTEMATIC REVIEW AND RESEARCH AGENDA PROPOSITION
}

\author{
Fernanda Bueno Cardoso Scussel
}

Fernanda Bueno Cardoso Scussel is a PhD student at the Graduate Program in Administration at the Federal University of Santa Catarina - UFSC. Email:

fbcardoso@gmail.com. This research was funded by CAPES - Coordination for the Improvement of Higher Education

Personnel. The authors thank the reviewers for their comments on improving the article.

\begin{abstract}
Literature recognizes consumer experience as an important construct to understand consumer behavior as well as the dominant basis for market differentiation. There is a growing body of knowledge on consumer experience, but little is known about the characteristics of its scientific production. Considering this, we performed a systematic review in order to provide an overview on consumer experience developments. We selected 414 articles for the final analysis and categorized them according to demographic, institutional and methodological criteria. Results indicated the predominance of empirical work, quantitative methods and organizational perspective. We concluded consumption experience is at the top of marketing agenda on research and practice, but it is still an incipient construct, lacking theoretical discussions, especially concerning its conceptualization, and the development of consumer perspective, which will lead consumer experience to the comprehension of consumption phenomena on its totality and complexity.
\end{abstract}

Keywords: Consumer experience, Literature review, Research agenda. 


\section{INTRODUCTION}

In consumer studies, the roots of consumer experience date to the 1960's with consumer buying behavior process models (Lemon \& Verhoef, 2016). In the 1970's, literature interest relies on customer satisfaction and loyalty, and this new scenario raises a focus on consumers' perceptions and attitudes towards their experiences. By that time, consumer experience was understood as a process related to product and service acquisition, used as a synonym for buying experience. However, this period saw the beginning of the debate on how experience would change economy and consumer behavior (Toffler, 1970) and, in the beginning of 1980's, consumer experience as a research tradition was initiated with the seminal article by Holbrook and Hirschman (1982).

Holbrook and Hirschman (1982) brought to consumer behavior body of knowledge important experiential aspects - fantasies, feelings and fun - so far neglected by process information models and economic theories. Therefore, consumer experience is conceived as a personal experience with emotional value, based on the interaction with products and services (Holbrook \& Hirshman, 1982). In the same decade, service management studies gained relevance identifying the context of consumer experience, its elements and the customer journey (Lemon \& Verhoef, 2016). According to Sundbo (2015), it was a turning point for service research: from an emphasis on service quality to service experience.

In the 1990's, relationship marketing emerges with an opening to consumers' responses, fundamental part of consumer experience (Lemon \& Verhoef, 2016). At the end of the decade, marketing literature watches the raise of the experience economy, a concept introduced by Pine and Gilmore (1999; 2013) that contributed to consolidate the interest of scholars on consumer experience, despite its managerial character. As reported by Addis and Holbrook (2001), this moment sets the transition from a traditional marketing perspective to the experiential perspective. Because of this change, the relevance of utilitarian function of products and services decreases at the same time symbolic value and meaning interest increases.
According to Sundbo (2015), the basis of consumer experience is the comprehension of the consumer not only as a buyer, but also as someone who engages with products and services in an experiential perspective. In this sense, consumer value in the experiential paradigm embraces functional, emotional, psychological and sociological perspectives. Consumer experience is considered an important source of competitive advantage, once it promotes emotional responses from consumers, affecting marketing variables such as purchase intention, satisfaction, loyalty and word-of-mouth behavior (Kranzbühler, Kleijnen, Morgan, \& Teerling, 2017; Scussel \& Petroll, 2018).

Palmer (2010) analyzed the evolution of the dominant basis for differentiation: from tangible design features to service benefits, relationships and, finally, experiential values. Similarly, Kranzbühler et al. (2017) indicated that early studies on experience have focused on extraordinary experiences with services encounter, going through service environment ambience, including tangible and intangible aspects and, more recently, embraces sensory marketing. Recently, Scussel and Petroll (2018) explained the connections between consumer experience and several marketing variables, revealing its antecedents - company and brand factors, consumer factors and interactional factors - and its consequences on consumer behavior intentions, brand-related outcomes, business performance, strategy development, innovation capability and relational outcome such as loyalty and recommendation intentions.

Based on the discussion above, the first objective of this article is to understand the relevance of consumption experience literature through an analysis of the latest developments on the field. As specific objectives, we intend to identify articles, authors, journals, universities and countries that studied this topic the most, and the methodological aspects used on the studies. The second objective of this study concerns the development of a research agenda on consumer experience. With these purposes, we aim to draw an overview of its evolution, understand why the concept is so important to marketing literature and provide guidance for future investigations. 


\section{THEORETICAL FRAMEWORK}

The term experience, used to indicate any individual's experience, became popular in the end of last century. Since then, each discipline uses the term accordingly to its interests: in philosophy, experience is a personal living that transforms the individual; in sociology and psychology, it refers to a cognitive activity that enables the individual's development; in anthropology, it is known as the wat individuals live their culture (Carù \& Cova, 2003).

The greatest attempt to bring experiential knowledge to consumer studies was with the seminal article of Holbrook and Hirshman (1982), when the authors conceive consumer experience as a personal experience someone has with products or services, produced by the interaction between them and characterized by high levels of emotions. The mentioned article has begun a new tradition in consumer research, putting light into the interaction factor and the need of creating consumer experiences in name of competitiveness (Lemon \& Verhoef, 2016; Pine \& Gilmore, 1999; 2013; Schmitt, 1999).

Pine and Gilmore (2013) evaluate that, since the launch of the experiential paradigm last century, many factors have contributed to the dissemination of this perspective and its research. Firstly, we must consider the changes in consumer thinking and the transformation of their expectations and demands. Next, individuals value experiences more than ever before, paying for experiences instead of collecting tangible objects available in the market for everyone - people want personalized meanings. Finally, from a managerial perspective, Pine and Gilmore
(2013) affirm that creating experiences is the only way to compete in the contemporary market.

According to Holbrook (1999), the first step to understand consumer experience is absorbing the notion of consumption event, in reference to the interaction between a subject the consumer - and an object of interest, which can be a product, a service or a destination. From the moment they start interacting, these two entities contribute to consumption experience: the object participates with its tangible characteristics and the subject participates with a series of subjective responses. For Addis and Holbrook (2001), the main difference between consumption event and consumption experience is the weight of consumers' subjective responses. To them, the event is linked to the utilitarian benefits of products - the traditional view about consumption; meanwhile the experience covers both utilitarian and hedonic values, bringing consumers' emotions during consumption to the interaction process.

Despite the interest in consumer experience, there is no consensus about its definition (Palmer, 2010; Pinto \& Lara, 2011; Sundbo, 2015; Jain et al., 2017; Keiningham, Ball, Benoit, Bruce, Buoye, Dzenkovska, Nasr, Ou, \& Zaki, 2017). As stated by Kranzbühler et al. (2017), the evolution of the understanding of consumer experience has produced a malleable concept, corresponding to the developments of each period of time it was used. Therefore, the term experience, in consumer field, is used and defined in several ways, some of them presented in Figure 1.

\begin{tabular}{|l|c|}
\hline \multicolumn{1}{|c|}{ Definition } & Reference \\
\hline $\begin{array}{l}\text { Consumer experience is a subjective state of the individual, conering a } \\
\text { range of symbolic meanings, hedonic responses and aesthetic criteria. }\end{array}$ & Holbrook e Hirshman (1982) \\
\hline $\begin{array}{l}\text { Consumer experience is an impression generated in the encounter of } \\
\text { consumers, products and services. }\end{array}$ & Carbone e Haeckel (1994, p. 8) \\
\hline $\begin{array}{l}\text { Consumer experience reflects consumer knowledge about the } \\
\text { elements of the experiential context, created by service providers. }\end{array}$ & Gupta e Vajic (1999) \\
\hline $\begin{array}{l}\text { Consumer experiences are events in which consumers engage with } \\
\text { companies in a personal way. }\end{array}$ & Pine e Gilmore (1999) \\
\hline $\begin{array}{l}\text { Consumer experience is an interaction or series of interaction } \\
\text { between consumer and a product, a company or its representant, } \\
\text { capable of producing a reaction in the consumer. }\end{array}$ & Lasalle e Britton (2002) \\
\hline
\end{tabular}




\begin{tabular}{|l|c|}
$\begin{array}{l}\text { Consumer experience is a set of activities and decisions during the } \\
\text { process of pre-purchase, purchase and after-purchase. }\end{array}$ & Carù e Cova (2003) \\
\hline $\begin{array}{l}\text { Consumer experience is the internal and subjective response of an } \\
\text { individual that has any contact with a company. }\end{array}$ & Meyer e Schwager (2007, p. 2) \\
\hline
\end{tabular}

Figure 1. Definitions of consumer experience found in literature

Kranzbühler et al. (2017) agree that consumer experience conforms an "umbrella construct", in reference to the diversity of definitions for the construct, the main reason, according to these scholars, consumer experience still is a topic of exponential interest, even if the thematic has been explored since the 1980's. In this sense, we still face the same conceptual misunderstandings since the introduction of experience and its subjective character in consumer studies (Addis \& Holbrook, 2001; Carù \& Cova, 2003; Holbrook, 1999; Holbrook \& Hirshman, 1982).

As discussed by Scussel and Petroll (2018), the roots of the conceptual confusion regarding consumer experience definition lies on the fact that the factors that form consumer experience have different roots. It is known that consumer has its role in the creation of his own experience (Lemon \& Verhoef, 2016); however, experience only happens in the interaction between consumer and organizational elements (Mascarenhas, Kesavan, \& Bernacchi, 2015). The result of this interaction is experiential value (Kranzbühler et al., 2017), an outcome that generates, on the consumer side, experiential benefits and, on the organizational one, experiential knowledge (Scussel \& Petroll, 2018). Thus, consumer experience cannot be addressed only as an internal response or as a synonym for a value proposition designed by companies, once it is an outcome of an interactional process (Scussel \& Petroll, 2018).

The first main misunderstanding regards the notion of consumer experience and service experience. Sundbo (2015) was the one to explain these constructs have different research focus, despite the fact they share many elements. The author explains service research cannot be substituted by consumer experience, as the last one must be explored under the experience economy paradigm. Similarly, Jain et al. (2017) agree service experience must be understood as a concept from service marketing literature. As proposed by Jain et al. (2017), the main distinction between service experience and consumer experience is the subject of the experience. The concept of service experience regards consumers or any other actor in this environment - consumer, service provider, other people in the organization; meanwhile the subject of consumer experience are the consumers - at the same time they produce the experience, they live the experience.

Another important difference to be addressed concerns the notion of extraordinary experience. The idea of experience as the new economic paradigm created, in the 1990's, the urge of designing extraordinary experiences, unexpected and unforgettable moments for consumers in an attempt of competitiveness (Carù \& Cova, 2003). Although the experiential notion has opened the scope of marketing to emotions and cognitions, it is important to understand that a consumer experience does not need to be extraordinary to generate emotions and meanings.

Differently from the ordinary consumption experiences, extraordinary experiences are characterized by high levels of emotions and intense feelings (Carù \& Cova, 2003), an emotional content that is remembered years later the experience, with the power of transforming individuals and creating consumer communities (Arnould \& Price, 1993). Literature conceives extraordinary experiences as an escape from daily activities and market strctures (Arnould \& Price, 1993; Belk \& Costa, 1998; Campbell, 1987; Firat \& Venkatesh, 1995; Tumbat \& Belk, 2011).

According to Scmitt (2011, p. 72), extraordinary experiences enable consumers to be connected in a "larger-than-life" phenomena, and this notion is close to the idea of flow experiences (Csikzentmihajyi, 1997), when consumers are highly engaged with an activity and its context, physically, emotionally and intellectually. We must clarify that extraordinary experience is not a great experience planned and executed by organizations in order to promote more interest in consumers, but a type of consumer 
experience, characterized be the intensity of the feelings and emotions during the process of consumption.

Recently, Scussel and Petroll (2018) presented the antecedents of consumer experience and the consequences of this construct. Three groups of antecedents were identified: (i) company and brand factors, covering physical, virtual and social environment; (ii) consumer factor, regarding consumer perceptions, technology acceptance and personality traits; and (iii) interaction factors, concerning previous experiences and the role of employees in building experience. As consequences, consumer experience generates consumer behavioral intentions and organizational consequences - brand related outcomes, such as trust and preference; managerial outcomes, associated to performance and strategy; and relational outcomes, such as loyalty and recommendation intentions.

Based on this, these authors developed a conceptual model to explain consumer experience process, in which consumers interact with value propositions designed by organizations, elaborating emotions, cognitions and feelings from the interaction. For its turn, interaction generates behavioral intentions, brand-related, managerial and relational outcomes that will become experiential value. Experiential value will turn into experiential benefits for consumers (concerning the level of appreciation of the experience and how the experience fits their needs and expectations) and experiential knowledge for organizations, which is used as fuel in the creation of new value propositions.

Pine and Gilmore (2013) revealed that since companies adopted experience as the new economy paradigm, research on this theme has strongly advanced in other to overcome the practical and managerial understanding of this concept. According to the authors, the consequence was the adoption of new methodologies and research techniques, with highlights to ethnography, a research strategy neglected for a long time by marketing scholars and practioners. However, as the world becomes more experiential, Pine and Gilmore (2013) report the need of focusing on consumer, their needs and desires, as most of the research so far has focused on the organizational perspective and its managerial implications.

Our literature review confirms the magnitude of consumer experience as a tradition in consumer studies; however, despite the theoretical and empirical advances in the last 30 years, this body of knowledge is still fragmented, with important building blocks without connection between them. We believe the process of putting these pieces together starts on theory development, especially concerning concept definition. Moreover, we must identify the gaps regarding experience in the consumer perspective, as Pine and Gilmore (2013) have recommended attention to this part of the interaction.

Considering this, we decided to explore the scientific characteristics of consumer experience literature, resorting to the latest developments in the field. We believe this comprehension can provide the roots for the advance in this body of knowledge, theoretically and empirically.

\section{METHOD}

To achieve the objectives of this paper, we have conducted a systematic review on consumer experience literature. As stated by Kitchenham (2004), systematic reviews help researchers to acknowledge, organize and summarize information on a specific topic, allowing them to draw conclusions about a specific phenomenon, being appropriate for the purposes of this article. According to Tranfied, Benyer and Smart (2003), systematic reviews need a detailed research protocol. Therefore, we followed the protocol of Dybå and Dingsøyr (2008), which recommends a successive article filtering process in four stages, as illustrated by Figure 2 .

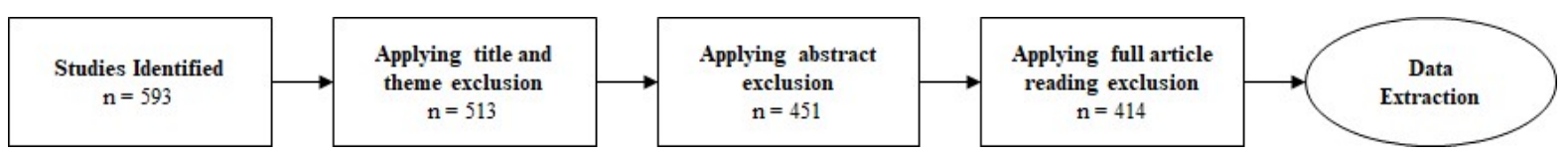

Source: adapted from Dybå and Dingsøyr (2008)

Figure 2. Research Protocol 
Initially, we conducted an exploratory phase to establish inclusion and exclusion criteria, based on previous literature review. We decided to include only peer-reviewed papers that analyze experience under consumption theories. Our search included studies from 2013 to 2017, in order to keep the latest developments in the field and to draw a realistic scenario of its scientific production. We set this date restriction based on the publication of the Handbook on the Experience Economy (Pine \& Gilmore, 2013), in which the authors update the last twenty year of debate on consumption experience. We accessed five databases (EBSCO, Emerald, ScienceDirect, Scopus and Google Scholar), to compare results and have a broader view on consumer experience from different perspectives. The keywords used were consumer experience, customer experience and consumption experience.

After the exploratory phase, we initiated the instructions from Dybå e Dingsøyr (2008). In the first stage, 593 articles were identified, using the keywords as inclusion criteria. The second stage covered title and keywords analysis to check the adherence to consumer experience. Duplicates must be excluded in this phase as well. At the end of second stage, 513 papers were kept. Third phase was abstract reading, which has generated a 451 papers sample. The last phase was full article reading, and the 451 papers were fully read in order to check if the articles converge with the research theme. A final sample of 414 articles was obtained.
Subsequently, we extracted data related to year of publication, authorship, journal and type of article (empirical or conceptual). Empirical articles were analyzed by nature of the research (qualitative, quantitative or multimethod), context of application and research design. The last step concerned the identification of the main themes developed by the papers. Afterwards, the relevant information was classified, summarized, analyzed and synthetized in order to identify the main characteristics of the scientific production on consumer experience.

\section{RESULTS}

This section presents a synthesis of the results obtained from the data extracted on the systematic review. From these outcomes, we elaborated an analysis of the scientific production on consumer experience, which raised a few reflections about the development of its knowledge, allowing us to propose a research agenda.

Firstly, we analyzed our paper sample by the year of publication. Results indicate a productive period, with an average of 82 articles by year and a growth trend, as the graphic on Figure 3 illustrates. Considering consumer experience a recent topic in marketing literature (Lemon \& Verhoef, 2016), the increase of publications reveals the potential of this subject in expanding and transforming marketing studies and practice.

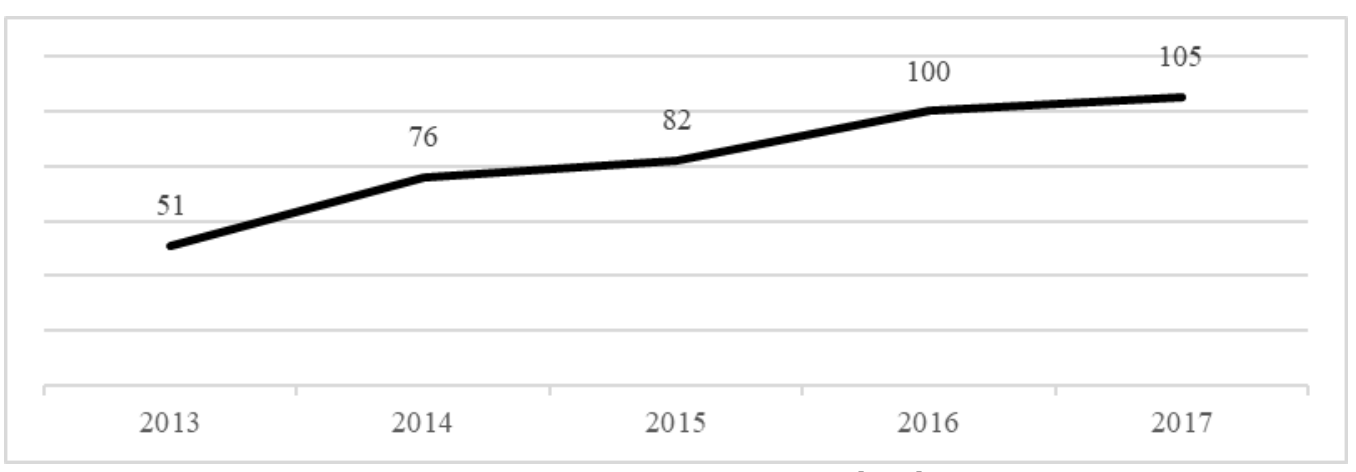

Figure 3. Consumer experience studies by year

In the following, we tracked the articles by author and co-authors. This action has led us to 967 researchers involved in consumer experience research. Considering this volume, we have decided to analyze the most productive names in the period, considering the researches with three or more papers. Table 1 summarizes the authors who published the most, their institutional affiliation and its country. 
Table 1

Main researchers on consumer experience

\begin{tabular}{lccc}
\hline \multicolumn{1}{c}{ Author } & Publications & Ins titution & Country \\
\hline Zillur Rahman & 7 & Indian Institute of Technology & India \\
Imran Khan & 6 & Indian Institute of Technology & India \\
Philipp Klaus & 6 & Cranfield University & United Kingdom \\
Edwin N. Torres & 5 & University of Central Florida & United States \\
Sajad Rezaei & 4 & Taylor's University & Malaysia \\
Wei Wei & 4 & University of Central Florida & United States \\
Anil Bilgihan & 3 & Florida Atlantic University & United States \\
Antonella Carù & 3 & Bocconi School of Management & Italy \\
Bernard Cova & 3 & Kedge Business School & France \\
Ching-Jui Keng & 3 & National Taipei University of Technology & Taiwan \\
Donald C. Barnes & 3 & University of North Carolina Wilmington & United States \\
Eleonora Pantano & 3 & University of Calabria & Italy \\
Frederic Ponsignon & 3 & University of Exeter & United Kingdom \\
Janet R. McColl Kennedy & 3 & The University of Queens land & Australia \\
Nan Hua & 3 & University of Wisconsin Eau Claire & United States \\
T. C. Melewar & 3 & Brunel University & United Kingdom \\
Tseng-Lung Huang & 3 & National Cheng-Chi University & Taiwan \\
Tze-Hsien Liao & 3 & Tatung University & Taiwan \\
\hline & & & \\
\hline
\end{tabular}

From these results, it is reasonable to say that research on consumer experience is pulverized, as it is a topic of interest of a substantial amount of scholars in a myriad of institutions around the globe. We also could not detect any research network, what enables us to assume there is not a concentration of research in a specific country or institution. From this, we assume consumer experience scientific production is a global construct, present in the most diverse contexts, in expansion phase.

Afterwards, we reviewed the articles by journal to identify the top 10 sources of publications. The International Journal of Culture, Tourism and Hospitality Research and the Journal of Retailing and Consumer Services share the first place with 21 publications each. Next, the European Journal of Marketing, the International Journal of Contemporary Hospitality Management and the International Journal of Hospitality Management appear in the second position with 18 articles each. The Journal of Business Research has 17 publications about consumer experience; the Journal of Service Management and the Journal of Services Marketing have 16 papers each; and the International Journal of Retail \& Distribution
Management published 15 articles in this matter during the analyzed period. These sources of publication are journals focused on tourism and hospitality, service management and strategic marketing. The only journal concentrated specific on consumer behavior is the Journal of Consumer Marketing, with 10 papers on consumer experience.

Next, we examined the articles by type to identify theoretical essays and empirical research. As a result, it was found the predominance of empirical articles (367) over theoretical discussions (47). This finding conducted us to a few considerations. First, consumer experience is a new construct in marketing literature, without an appropriate definition (Jain et al., 2017). In this sense, a construct under development needs further conceptual and theoretical debate, once a consolidated concept will allow better understanding of its roots, purpose, implications, measurements and the relationships with other variables. Therefore, our findings indicate the insufficiency of conceptual works, especially when we compare with the amount of theoretical and empirical works in the context of a construct in 
development. Second, it is important that empirical research also meet this issue.

The empirical articles were first analyzed by the nature of the research. We identified 232 quantitative works, 121 qualitative papers and 14 multimethod articles. The quantitative and the multimethod studies are aligned with positivist philosophy, as well as 57 qualitative studies. According to Scussel (2017), positivist studies in marketing serve a managerial interest, with the main goal of developing market knowledge, resorting to a formal logic. The other 64 qualitative papers were developed under alternative approaches, consonant to an interpretativist logic, which aims for social phenomena understanding by communication and interpretation. These studies follow a subjective analysis and privilege consumer perspective over organizational perspective (Scussel, 2017).

This though led us to analyze the empirical articles by perspective. We observed the prevalence of organizational perspective (220) over consumer perspective (147). These results indicate the supremacy of studies on business strategy, managerial implications and experience design to attract and retain customers, impact on word-of-mouth and, as consequence, promote organizational performance. Our interpretation meets the traditional marketing thought and its roots on strategy and competitive advantage creation (Sheth, Gardner, \& Garrett, 1988).

Regarding the studies on consumer perspective, considering its convergence with a positivist approach, it is valid to say they fulfill the objective of market knowledge creation on how consumers react to organizational stimulus. Once again, there is a confluence with strategy, considering that positive associations on consumers' minds lead to higher competitive positions (Keller \& Lehmann, 2006).

We also tracked the context of application of the empirical researches, so we could recognize the top 10 market segments were consumer experience is valued the most. Tourism and hospitality industry constitutes an important research field for consumer experience, with 109 publications. Food and beverage sector shares the second position with retail with 37 papers each. E-commerce comes in third place, with 35 articles, followed by service companies (17), entertainment industry (16) and information technology and communications (13). Banks, supermarkets and fashion retail are next, with nine publications each. Lastly, eight studies were developed in the context of shopping malls.

The results obtained on the tourism and hospitality, food and beverages, and entertainment industries are aligned with the main experiential aspects of consumption, as described by Holbrook and Hirshman (1982), once it is important to put light on elements such as fantasies, fun, feelings and emotions. These authors believe that experience should be a personal experience with emotional value that happens when consumers interact with products and services. These outcomes also put light on technology as a mediator of the interaction between consumer and brands, firms, products and services, once online shopping and online communication constitute a growing trend, changing the way consumers relate to companies and how they search, perceive and buy experience.

Next, we accessed research design. Concerning data collection, a considerable amount of studies used more than one data collection technique to achieve their objectives. On this matter, we identified an array of means used by researchers to study consumer experience. The findings indicate the prevalence of structured questionnaires, used on the 208 surveys and 34 experiments analyzed in our systematic review. Considering the predominance of quantitative studies, this is a presumable result. Subsequently, interviews were used in 83 works, revealing the power of this qualitative technique. Netnography was present in 22 articles. In the following, we have non-participating observation (13), focus group (10), case study (9), narratives (8) and ethnography.

After that, we investigated the top ten data analysis techniques. We recognize the prevalence of statistical analysis, corroborating the amount of quantitative papers, but also the advances on organizational perspective and its predictive character. The most used analysis technique was structural equation modeling (100), followed by confirmatory factor analysis (51), exploratory factor analysis (45), regression (37), ANOVA (29), variance analysis (6) and MANOVA (6). On the qualitative side, we have the predominance of content analysis, 
used by 61 articles, corroborating our finding that interviews are the most used data collection technique. Narrative analysis comes next with 19 papers and social networks analysis was employed in 13 papers. In a few cases, more than one data analysis technique was used, eight articles declared to have used data triangulation.

Lastly, we reassessed empirical articles in order to identify the main themes developed on the papers. Tables 2 illustrates our findings.

Table 2

Main themes developed under consumer experience

\begin{tabular}{lc}
\hline \multicolumn{1}{c}{ Theme } & Publications \\
\hline Consumer experience design & 72 \\
Consumer experience antecedents & 48 \\
Holistic experience & 47 \\
Consequences of consumer experience & 42 \\
Customer experience management & 38 \\
Service experience & 25 \\
Online consumer experience & 20 \\
Consumer subjective experience & 17 \\
Brand experience & 15 \\
Experiential value & 14 \\
Consumer experience dimensions & 10 \\
City experience & 8 \\
Product experience & 6 \\
Shopping experience & 5 \\
\hline Total & $\mathbf{3 6 7}$ \\
\hline
\end{tabular}

As Table 2 shows, the main debate on consumer experience literature are the building blocks of consumer experience: how to create a positive experience, the elements of the experience, its determinants and outcomes. This interest has a strategic nature, once the findings from studies in this perspective contribute with business strategy formulation and helps the development of new products and services. Consumer experience management is also an important topic, close to service experience and its managerial character. In this sense, there is an interest in discovering how consumer experience affects other variables such as satisfaction, loyalty, word-of-mouth, consumer attitude, behavioral intentions and relationship between clients and companies.

This result is another evidence of the organizational focus of consumer experience literature, once the design of the experience implies the analysis of organizational efforts on developing value proposition that will be noticed by consumers and transformed in experiences. Most of the studies focus on customer journey and the interaction points between consumer and company during the experience. Our findings also reveal the growing interest on user experience, the interaction between consumer and virtual context and the impacts of technology on consumer experience. Finally, experience co-creation was found to be an important topic for consumer experience research development, once it brings consumer and organizational perspectives together, setting a win-win situation in which both parties perceive benefits from the interaction.

Table 2 also shows another research tradition, focused on the consumer side of the experience. Studies dedicated to consumer subjective experience bring light to consumer perspective: emotions, perceptions, feelings and the meanings of the experience. These studies embrace the transformations experience can make in consumers' lives. This finding indicates the growing concern with the subjacent aspects of consumption that affect and change 
consumer experience, context in which the impact of experience in the individual's life is the main interest of investigations.

In this regard, literature recognizes the importance of qualitative approaches, once they open opportunities to explore symbolic elements of consumption experience, as well as the relation consumers develop with symbols, meanings and emotions inherent to their experiences. Nevertheless, this does not mean quantitative approach must be discredited, since most of the advances made in consumer experience studies, as our findings point out, lie on quantitative research and this perspective generates valid and reliable contributions.

What we have identified is an opening to alternative methods, embracing both qualitative and quantitative approaches. In our view, a step further should be taken: we do not need to stay on one side or the other, as they are not opposite, but complementary, and use this permeability to improve our skills as researchers, combining the precision from statistics with the depth of qualitative techniques.

\section{RESEARCH AGENDA PROPOSITION}

Considering the results from the previous section, we believe the most important gap to be pursued in future investigations is the development of an appropriate definition for consumer experience. It is a consensus that literature needs an appropriate definition for the construct (Palmer, 2010; Sundbo, 2015; Lemon \& Verhoef, 2016; Kranzbühler et al., 2017). Although this lacuna is not a surprise, it has not been fulfilled, raising a question: what are the reasons to this absence?

We recognize that scientific production on consumer experience privileges empirical researches. The consequence of this, considering consumer experience as a new tradition in marketing studies, is an empirical foundation instead of a theoretical foundation. We understand this is caused by the predominance of a managerial perspective - as proposed by Pine and Gilmore (2013), the interest in experience has its origins in market practice, followed by academic interest. This is not wrong, we must say. This is not a critic. Our intention is to start a reflection about the need of theory development, based on the idea that progress in the theoretical field will contribute to fill the empirical gaps and to connect the experiential context elements. We must walk towards consolidating consumer experience construct, which means developing a strong theoretical framework that supports future empirical findings.

There is also the inadequate use of consumer experience and service experience as synonyms (Jain et al., 2017). This conceptual confusion may be a consequence of the focus on organizational perspective. Its understanding of consumer experience as an organizational attribute, context in which excellence in service creates emotional responses on customers, generates behavioral intentions and leads to better revenues and business performance. The preponderance of quantitative researches may have an association with this lack of conceptual accordance as well. At last, the few exploratory studies investigating how consumer experience occurs on consumers' minds and among different consumers' groups can contribute with this scenario. Therefore, we strongly advise theoretical essays in order to meet this necessity. Efforts in this sense can also include the creation of research groups, online discussion forums, conceptual debates on conferences and meetings and call for papers.

Another important topic in our research agenda highlights the context of research. We observed that consumer experience has been investigated in traditional marketing segments, such as tourism, retail, banks, technology and service companies. It is important to expand the context of our works, considering the experience of consumers with public organizations, healthcare system, government and the third sector, as examples. This consideration leads us to the need of strengthening consumer perspective.

The theoretical works analyzed in this systematic review attest literature focus on organizational-related themes, especially those focused on experience design, experience creation among corporative customers, service experience and customer loyalty on experience economy. In this sense, conceptual developments corroborate the empirical articles, confirming the prevalence of studies dedicated to the organizational perspective, with reduced attention to consumer perspective. As we observe, the comprehension 
about consumers' role on consumption experience must be addressed.

Literature needs to acknowledge the resources consumers bring to the interaction context during experience creation, their roles on experience context, their feelings and the meanings involved, as well as the impact of this in consumers daily routine and life experience as a whole. Our findings confirm the need of exploring the holistic nature of consumer experience (McColl-Kennedy, Gustafsson, Jaakkola, Klaus, Radnor, Perks, \& Friman, 2015). Regarding that, we recommend future investigations not only explore interactions between consumers and firms, brands, products and services, but also which interactions can generate consumer experience and how consumer reaction changes as time goes by.

According to Scussel (2017), consumption society comprehension demands the study of phenomena on its totality, embracing its history and context. In this sense, the author suggests the adoption of complexity as a starting point on marketing studies: consumption phenomena should not be investigated in isolated parts, but as an effort to comprehend and reveal the relationship between these parts.

Considering the above, the need of broadening our view about consumer experience and the predominance of quantitative studies over qualitative works, we believe alternative research designs may contribute to the theoretical and empirical development of the construct. In this respect, qualitative studies with an interpretative approach are welcome, as well as methodologies that allow the comprehension of consumption phenomenon as a whole, such as ethnography. Moreover, netnography has shown to be very helpful in understanding the impact of technology and internet on consumer behavior (Kozinets, 2014), being an alternative to explore the online consumer experience.

\section{CONCLUSION}

The main objective of this study was to analyze the characteristics of the scientific production on consumer experience. We examined 414 articles published between 2013 and 2017, a productive period for the construct that revealed a growth trend. Consumer experience is a topic of major interest in marketing literature, studied buy a great number of researchers around the globe, from different institutions and countries, revealing a pulverized scientific production. The International Journal of Culture, Tourism and Hospitality Research and the Journal of Retailing and Consumer Services are the main sources of publications in the investigated period, as well as Zillur Rahman, Irmran Khan and Philipp Klaus are the authors that published the most.

Results demonstrated the prevalence of empirical researches over theoretical essays and the preference of researchers for quantitative methods and organizational perspective. Tourism and hospitality industry was the preferred context of application of empirical studies. Surveys and interviews are the most used data collection technique and, concerning data analysis, statistical analysis and content analysis are the favorite ones. As the main themes discussed on consumer experience, there is an inclination for consumer experience design and its elements and outcomes. Concerning research design, there is an opening for alternative methods, especially qualitative techniques from an interpretativist approach, which we believe that will help literature advance on consumer perspective. These findings enable us to propose a research agenda, in which we highlight the urge of theoretical development and an appropriate definition for consumer experience construct.

Regarding limitations, our sample was restricted to four databases and did not cover the entire existing literature on the topic. Moreover, we only reviewed journal articles. In this case, working papers from conferences, theses, dissertations and books contribute to the development of consumer experience studies. Another limitation is the period selected for our analysis, the last five years. Although it does not cover the scientific production since its beginning on the 1980's, we have tracked a significant amount of work on consumer experience, describing the most recent findings on this matter and providing guidance for future investigations.

For future researches, we recommend periodic updates of the characteristics examined in this article. The same can be performed for conference papers and doctoral works, once they are work in progress and their analysis may indicate new trends for scientific 
production. It is also interesting that this kind of analysis are conducted for countries' national production, investigating specific contexts and also enabling future cross-country comparisons. This may approximate researches around the globe with similar interests, strengthening the literature on consumer experience.

This article has presented an overview of scientific production on consumer experience, based on the latest developments of the field, revealing what has been done, what is in progress and, most importantly, the inconsistencies and the gaps that need further attention. This information conforms the major contribution of this work: to provide elements through the proposition of a research agenda that will guide the efforts of researchers, conference coordinators, professors and institutions in fulfilling the theoretical and empirical gaps. As managerial implications, our review indicates important issues to be developed by firms in order to formulate strategies, design value propositions and create value for customers.

Although the great volume of publications and the growing interest of marketing scholars on the topic, consumer experience literature is in an expansion phase, especially concerning its conceptual framework. Despite of the need of theoretical development and conceptualization, consumer experience proved to be a subject of great significance to marketing literature development. The number of publications, the growth trend and the volume of organizational perspective studies demonstrated that consumer experience not only is shaping consumer behavior and business management studies, but also affects the way companies and brands conduct their strategies and relate to customers. For this, we risk to say: consumer experience is the next best thing. Researches may face challenges on fulfilling the lacunas of its literature, but they will contribute to a broaden comprehension of consumption phenomena.

\section{REFERENCES}

Addis, M., \& Holbrook, M. B. (2001). On the conceptual link between mass customisation and experiential consumption: an explosion of subjectivity. Journal of Consumer Behaviour, 1(1), 50-66.
Arnould, E. J., \& Price, L. L. (1993). River magic: Extraordinary experience and the extended service encounter. Journal of Consumer Research, 20(1), 24-45.

Belk, R. W., \& Costa, J. A. (1998). The mountain man myth: A contemporary consuming fantasy. Journal of Consumer Research, 25(3), 218-240.

Campbell, C. (1987) The Romantic Ethic and the Spirit of Modern Consumerism. Oxford:

Carbone, L. P., \& Haeckel, S. H. (1994). Engineering customer experiences. Marketing Management, 3(3), 8-19.

Carù, A., \& Cova, B. (2003). Revisiting consumption experience: A more humble but complete view of the concept. Marketing Theory, 3(2), 267286.

Csikszentmihalyi, M. (1997). Flow and the psychology of discovery and invention. HarperPerennial, New York, 39.

Dybå, T., \& Dingsøyr, T. (2008). Streingth of evidence in Systematic Reviews in software engineering. Empirical Software Engineering and Measurement (ESEM), 8.

Firat, A. F., \& Venkatesh, A. (1995). Liberatory postmodernism and the reenchantment of consumption. Journal of Consumer Research, 22(3), 239-267.

Gupta, S. V., \& Vajic, M. (1999). M. (1999). The Contextual and Dialectical Nature of Experiences. New Service Development: Creating Memorable Experiences, ed. J. Fitzimmons, M. Fitzimmons, 33-35.

Holbrook, M. B., \& Hirschman, E. C. (1982). The experiential aspects of consumption: Consumer fantasies, feelings, and fun. Journal of Consumer Research, 9(2), 132-140.

Jain, R., Aagja, J., \& Bagdare, S. (2017). Customer experience-A review and research agenda. Journal of Service Theory and Practice, 27(3), 642-662.

Keiningham, T., Ball, J., Benoit, S., Bruce, H. L., Buoye, A., Dzenkovska, J., ... \& Zaki, M. (2017). The interplay of customer experience and commitment. Journal of Services Marketing, 31(2), 148-160.

Keller, K. L., \& Lehmann, D. R. (2006). Brands and branding: Research findings and future priorities. Marketing Science, 25(6), 740-759.

Kitchenham, B. (2004). Procedures for performing systematic reviews. Keele, UK, Keele.

Kozinets, R. V. (2014). Netnografia: realizando pesquisa etnográfica online. Penso Editora.

Kranzbühler, A. M., Kleijnen, M. H., Morgan, R. E., \& Teerling, M. (2017). The multilevel nature of customer experience research: an integrative review and research agenda. International Journal of Management Reviews. 
LaSalle, D., \& Britton, T. A. (2002). Priceless: Turning ordinary products into extraordinary experiences. Harvard Business School Press.

Lemon, K. N., \& Verhoef, P. C. (2016). Understanding customer experience throughout the customer journey. Journal of Marketing, 80(6), 69-96.

Mazzon, J. A., \& Hernandez, J. M. D. C. (2013). Brazilian scientific production in marketing in the period 2000-2009. Revista de Administração de Empresas, 53(1), 67-80.

McColl-Kennedy, J. R., Gustafsson, A., Jaakkola, E., Klaus, P., Radnor, Z. J., Perks, H., \& Friman, M. (2015). Fresh perspectives on customer experience. Journal of Services Marketing, $29(6 / 7), 430-435$.

Meyer, C., \& Schwager, A. (2007). Understanding customer experience. Harvard business Review, 85(2), 116.

Palmer, A. (2010). Customer experience management: a critical review of an emerging idea. Journal of Services Marketing, 24(3), 196208.

Pine, B. J., \& Gilmore, J. H. (1999). The experience economy: work is theatre \& every business a stage. Harvard Business Press.

Pine, B. J., \& Gilmore, J. H. (2013). The experience economy: past, present and future. Handbook on the experience economy, 21-44.
Scussel, F. B. C. (2017). Poder, paradigmas e domínio na pesquisa em marketing no Brasil: uma análise da produção nacional da disciplina a partir das matrizes epistêmicas. Administração: Ensino e Pesquisa, 18(3), 518557.

Scussel, F. B. C.; Petroll, M. L. M. (2018). A conceptual framework to explain consumption experience process: building theory from a systematic review. Anais. XLII Encontro da ANPAD (EnANPAD), Curitiba.

Sheth, J. N., Gardner, D. M., \& Garrett, D. E. (1988). Marketing theory: evolution and evaluation (Vol. 12). John Wiley \& Sons Inc.

Sundbo, J. (2015). From service quality to experience-and back again? International Journal of Quality and Service Sciences, 7(1), 107-119.

Tofler, A. (1970). Future Shock, 1, New York, NY: Bentam Book.

Tranfield, D., Denyer, D., \& Smart, P. (2003). Towards a methodology for developing evidenceinformed management knowledge by means of systematic review. British Journal of Management, 14(3), 207-222.

Tumbat, G., \& Belk, R. W. (2011). Marketplace tensions in extraordinary experiences. Journal of Consumer Research, 38(1), 42-61.

\section{A experiência de consumo é isso tudo mesmo? Reflexões a partir de uma revisão sistemática e proposta de uma agenda de pesquisa}

\section{Resumo}

A literatura reconhece a experiência de consumo como um importante construto na compreensão do comportamento do consumidor, revelando-se a base dominante da diferenciação de mercado. Um crescente corpo de conhecimento em experiência de consumo vem tomando forma, embora pouco se saiba sobre as características de sua produção científica. Diante disso, realizamos uma revisão sistemática para apresentar um panorama dos estudos nesta temática. Foram selecionados 414 artigos, categorizados de acordo com critérios demográficos, institucionais e metodológicos. Os resultados indicaram a predominância de artigos empíricos, métodos quantitativos e da perspectiva organizacional. Concluímos que a experiência de consumo está no topo da agenda de pesquisa e da prática em marketing, mas ainda configura um construto incipiente, haja vista a ausência de discussões teóricas, especialmente em relação à sua conceitualização, além do desenvolvimento da perspectiva do consumidor, o que conduzirá a experiência de consumo à compreensão dos fenômenos de consumo em sua totalidade.

Palavras-chave: Experiência de consumo, Revisão de literatura, Agenda de pesquisa. 